\title{
Changes in the rates of awareness, treatment and control of hypertension in Canada over the past two decades
}

\author{
Finlay A. McAlister MD MSc, Kathryn Wilkins MSc, Michel Joffres MD PhD, Frans H.H. Leenen MD PhD, \\ George Fodor MD PhD, Marianne Gee MSc, Mark S. Tremblay PhD, Robin Walker MSc, Helen Johansen PhD, \\ Norm Campbell MD
}

See related commentary by Chobanian on page 996 and at www.cmaj.ca/cgi/doi/10.1503/cmaj.110635.

\section{- ABSTRACT}

Background: Analyses of medication databases indicate marked increases in prescribing of antihypertensive drugs in Canada over the past decade. This study was done to examine the trends in the prevalence of hypertension and in control rates in Canada between 1992 and 2009.

Methods: Three population-based surveys, the 1986-1992 Canadian Heart Health Surveys, the 2006 Ontario Survey on the Prevalence and Control of Hypertension and the 2007-2009 Canadian Health Measures Survey, collected self-reported health information from, and measured blood pressure among, communitydwelling adults.

Results: The population prevalence of hypertension was stable between 1992 and 2009 at $19.7 \%-21.6 \%$. Hypertension control improved from $13.2 \%$ (95\% confidence interval $[\mathrm{Cl}]$ $10.7 \%-15.7 \%)$ in 1992 to $64.6 \%(95 \% \mathrm{Cl} 60.0 \%$ $69.2 \%$ ) in 2009, reflecting improvements in awareness (from $56.9 \%$ [95\% Cl 53.1\%-60.5\%] in 1992 to $82.5 \%$ [ $95 \% \mathrm{Cl} 78.5 \%-86.0 \%$ ] in
2009) and treatment (from $34.6 \%[95 \% \mathrm{Cl}$ $29.2 \%-40.0 \%$ ] in 1992 to $79.0 \%$ [ $95 \%$ Cl $71.3 \%$ $86.7 \%$ ] in 2009) among people with hypertension. The size of improvements in awareness, treatment and control were similar among people who had or did not have cardiovascular comorbidities Although systolic blood pressures among patients with untreated hypertension were similar between 1992 and 2009 (ranging from 146 [95\% Cl 145-147] $\mathrm{mm} \mathrm{Hg}$ to 148 [95\% Cl 144-151] mm Hg), people who did not have hypertension and patients with hypertension that was being treated showed substantially lower systolic pressures in 2009 than in 1992 (113 [95\% Cl 112-114] v. 117 [95\% Cl 117-117] $\mathrm{mm} \mathrm{Hg}$ and $128[95 \% \mathrm{Cl} 126-130]$ v. $145[95 \%$ Cl 143-147] $\mathrm{mm} \mathrm{Hg}$ )

Interpretation: The prevalence of hypertension has remained stable among communitydwelling adults in Canada over the past two decades, but the rates for treatment and control of hypertension have improved markedly during this time.
$\mathrm{E}$ levated blood pressure is the most important modifiable risk factor for vascular disease and mortality in developed nations. ${ }^{1}$ There is a strong log-linear relationship between blood pressure levels and vascular outcomes, ${ }^{2}$ and there is robust evidence from randomized trials showing that reducing blood pressure can prevent cardiovascular events (particularly stroke). ${ }^{3}$ Although audits throughout the 1990s consistently showed suboptimal control of blood pressure in clinical practice, ${ }^{4}$ recent analyses of multiple Canadian datasets have suggested marked improvements in the prescribing rates for antihypertensive medications over the past decade, with attendant decreases in hypertension-related cardiovascular events. ${ }^{5,6}$

A recent population-based direct measures survey from Ontario suggested that control of hypertension had improved nearly fivefold in Ontario between 1992 and 2006. ${ }^{7}$ Given the size of this apparent change and its inconsistency with the results of surveys from other countries, ${ }^{8-10}$ questions arose as to whether the changes seen in Ontario were representative of the management of hypertension nationwide.

The purpose of our study was to review the key findings from the last two national surveys conducted in Canada in which blood pressure was directly measured among community-dwelling adults - the 1986-1992 Canadian Heart Health Surveys (CHHS) ${ }^{11}$ and the 2007-2009 Canadian Health Measures Survey (CHMS) ${ }^{12}$ - and to place these results in context with the results from the 2006 Ontario Survey on the Prevalence and Control of Hypertension (ON-BP). ${ }^{7}$

Although the results of the automated blood
Competing interests:

Frans Leenen and George Fodor have received grants from the Heart and Stroke Foundation of Ontario. Helen Johansen has received support for travel expenses from The Public Health Agency of Canada. Norm Campbell receives a portion of his salary from the Canadian Institutes of Health Research; he was a member of the board of Bristol-Myers SquibbSanofi in 2009; he has received payment for lectures from Bayer, BristolMyers Squibb, Sanofi, Aventis and Biovail, he has been reimbursed for travel and meeting expenses by Boeringer Ingelheim. No other competing interests were declared.

This article has been peer reviewed.

Correspondence to: Dr. Finlay A. McAlister, finlay.mcalister@ualberta.ca

CMAJ 2011. DOI:10.1503 /cmaj.101767 
pressure measurements from the CHMS have been previously published for the entire cohort, ${ }^{12}$ the blood pressures reported in this manuscript have been adjusted to account for differences in the measurement techniques used between surveys. We also had access to additional information from all three surveys that allowed us to stratify our analyses by comorbidity status.

\section{Methods}

The methods used in the CHHS, ON-BP and CHMS have been described in full elsewhere. ${ }^{7,11,12}$ Each of the surveys targeted a sample of participants across geographic regions but excluded people living in long-term care facilities. Participants in all three surveys were asked health-related questions in person and had their blood pressures measured.

In the CHHS, blood pressure was measured using a mercury sphygmomanometer and the average of four readings was recorded. In the CHMS and ON-BP surveys, blood pressure was measured using an electronic oscillometric monitor (BpTRU Medical Devices Ltd., Coquitlam, British Columbia) and the average of five readings was recorded. ${ }^{7,12}$ For the purposes of our analyses, measurements from the ON-BP and CHMS surveys were converted to the expected manual sphygmomanometer readings using previously validated linear regression equations: ${ }^{13}$ adjusted $\mathrm{SBP}=11.4+\left(0.93 \times \mathrm{SBP}_{\mathrm{BpTRU}}\right) ;$ and adjusted $\mathrm{DBP}=15.6+\left(0.83 \times \mathrm{DBP}_{\mathrm{BpTRU}}\right.$, where DBP is diastolic blood pressure, $\mathrm{DBP}_{\mathrm{BpTRU}}$ is the diastolic blood pressure measured using the BpTRU monitor, SBP is systolic blood pressure, and $\mathrm{SBP}_{\mathrm{BpTRU}}$ is the systolic blood pressure measured using the BpTRU monitor.

We limited our analyses in all three surveys to participants aged 20 years or older and excluded any women who were pregnant. In all three surveys, hypertension was defined as a mean systolic blood pressure greater than $140 \mathrm{~mm} \mathrm{Hg}$, a mean diastolic blood pressure greater than $90 \mathrm{~mm} \mathrm{Hg}$ or self-reported daily use of blood pressure medication during the previous month. In a sensitivity analysis, a person with self-reported diabetes was defined as having hypertension if his or her mean systolic blood pressure was greater than $130 \mathrm{~mm} \mathrm{Hg}$ or if his or her diastolic blood pressure was greater than $80 \mathrm{~mm} \mathrm{Hg}$. Participants who self-reported a diagnosis of hypertension but who were not receiving treatment and had normal blood pressures were not defined as having hypertension (51 participants from the CHMS). We defined participants with hypertension as having "controlled" blood pressure if their systolic blood pressure was less than $140 \mathrm{~mm} \mathrm{Hg}$ and their dia - stolic blood pressure was less than $90 \mathrm{~mm} \mathrm{Hg}$; participants were defined as having "uncontrolled" blood pressure if either of these limits were exceeded. In a sensitivity analysis, people with self-reported diabetes were defined as having "uncontrolled" blood pressure if their systolic blood pressure was greater than $130 \mathrm{~mm} \mathrm{Hg}$ and their diastolic blood pressure was greater than $80 \mathrm{~mm} \mathrm{Hg}$.

Survey weights generated by Statistics Canada were applied to the data from each of the three surveys. The weighted CHMS data were analyzed with SAS and SUDAAN software, using 11 denominator degrees of freedom in the SUDAAN procedure statements (SAS version 9.1, SAS Institute Inc., Cary, North Carolina). Mean values of systolic and diastolic blood pressures and estimates of hypertension and hypertension control were calculated. To account for the complex design of the CHMS, variance was estimated using bootstrap weights. ${ }^{14}$

\section{Results}

The household response rates for the three surveys were comparable $(76.8 \%$ for the CHHS, $65.6 \%$ for the ON-BP and $69.6 \%$ for the CHMS), and similar proportions of household participants had their blood pressures measured in each survey (85.2\% for the CHHS, $85.3 \%$ for the ON-BP and $83.6 \%$ for the CHMS). All three surveys enrolled demographically similar populations: $50.9 \%$ of the participants in the CHHS and ON-BP and $53.1 \%$ of the participants in the CHMS were women. The age ranges included in our analyses were 20-79 years for the ON-BP (mean 45 years), 20-79 years in the CHMS (mean 46 years) and 20-74 years for the CHHS (mean 41 years).

The population prevalence of hypertension estimated from each survey was stable: $21.6 \%$ of the adult population in 1992 (25.5\% of men and $17.8 \%$ of women), $21.3 \%$ of the adult population in 2006 (23.8\% of men and $19.0 \%$ of women), and $19.7 \%$ of the adult population in 2009 (19.9\% of men and $19.4 \%$ of women). When people who reported having diabetes and had a systolic blood pressure of $130-140 \mathrm{~mm} \mathrm{Hg}$ or a diastolic blood pressure of $80-90 \mathrm{~mm} \mathrm{Hg}$ were included in the number of people with hypertension, prevalence rates increased by $0.5 \%$ in 1992 (CHHS), $1.3 \%$ in 2006 (ON-BP) and $0.7 \%$ in 2009 (CHMS).

Average systolic blood pressures were similar in the sample populations from the ON-BP and the CHMS; these averages were substantially lower than the averages seen in the CHHS among all subgroups (Table 1). Although the values for systolic and diastolic blood pressures among people with untreated hypertension (an 
amalgam of those who were unaware of their condition and those who were aware but were not taking any antihypertensive medications) were similar in all three surveys, people who were receiving treatment for hypertension and participants who did not have hypertension had substantially lower systolic blood pressures in 2006 and 2009 compared with 1992 (Table 1).

The proportion of Canadians with hypertension who were aware of their condition and who were either not receiving treatment or receiving treatment that was not controlling their blood pressure dropped between 1992 and 2009 (Figure 1, Table 2). A much sharper decline in the proportion of people with hypertension who were unaware of their condition (from $43.2 \%$ to $17.4 \%$, $p<0.001)$ was observed over this timeframe. The proportion of Canadians with hypertension whose blood pressure was under control and below 140/90 $\mathrm{mm} \mathrm{Hg}$ increased from $13.2 \%$ in 1992 to $64.6 \%$ in 2009 ( $p<0.001$, Figure 1, Table 2). When controlled blood pressure for patients with diabetes was defined as $130 / 80 \mathrm{~mm} \mathrm{Hg}$ or lower, then overall control rates increased from $12.1 \%$ in 1992 to $58.9 \%$ in 2009.

Among people who were receiving treatment but whose blood pressure was not under control, most had systolic blood pressures higher than $140 \mathrm{~mm} \mathrm{Hg}$. In 2009, the proportion of these people was $81.8 \%$, compared with $80.2 \%$ in 2006 and $90.6 \%$ in $1992 ; 40.9 \%$ of the participants to the CHMS had diastolic blood pressures exceeding $90 \mathrm{~mm} \mathrm{Hg}$, compared with $32.4 \%$ of ON-BP participants and $52.7 \%$ of CHHS participants.

The prevalence of hypertension in people with comorbidities was relatively stable among all three surveys, with similar reductions over time in the proportions who were unaware of their condition or who were aware of their condition but not seeking treatment (Table 2). Of note, people with hypertension who had previously had a myocardial infarction or stroke were more likely to have controlled blood pressure than people with hypertension who had not previously had one of these events. This was true for both the 1992 and the 2009 data (1992 odds ratio [OR] 2.1 [95\% CI 1.2-3.6] and 2009 OR 3.0 [95\% CI 1.8-5.0]). Although there were strong trends toward better control of blood pressure (defined as lower than 140/90 mm Hg) in participants with hypertension who also reported having diabetes (1992 OR 1.6 [95\% CI 0.9-2.8] and 2009 OR 2.0 [95\% CI 0.9-4.5]) or dyslipidemia (1992 OR 1.6 [95\% CI 0.9-2.5] and OR 1.5 [95\% CI 0.9-2.4]) when compared with participants who did not report these conditions, these trends did not achieve statistical significance in either the 1992 or the 2009 data.

\section{Discussion}

The management of hypertension among community-dwelling Canadian adults appears to have improved over the past two decades. Notably, the rates of awareness, treatment and control documented in the ON-BP and the CHMS are higher than those recently reported from physical measures surveys done in the United States ${ }^{10}$ and elsewhere during the same periods. ${ }^{8,9}$ These

Table 1: Mean blood pressure values from three population-based surveys conducted between 1992 and 2009 in Canada

\begin{tabular}{|c|c|c|c|}
\hline \multirow[b]{2}{*}{ Characteristic } & \multicolumn{3}{|c|}{ Mean blood pressure, $\mathrm{mm} \mathrm{Hg}(95 \% \mathrm{Cl})$} \\
\hline & $\begin{array}{l}\text { CHHS } \\
(1986-1992) \\
n=22314\end{array}$ & $\begin{array}{l}\text { ON-BP } \\
(2006) \\
n=2551\end{array}$ & $\begin{array}{c}\text { CHMS } \\
(2007-2009) \\
n=3487\end{array}$ \\
\hline \multicolumn{4}{|l|}{ Systolic } \\
\hline \multicolumn{4}{|l|}{ Sex } \\
\hline Male & $128(128-128)$ & $118(117-113)$ & $118(117-120)$ \\
\hline Female & $120(120-121)$ & $114(113-116)$ & $115(114-116)$ \\
\hline \multicolumn{4}{|l|}{ Age groupings, yr } \\
\hline Male, 20-39 & $123(123-123)$ & $115(113-116)$ & $114(112-115)$ \\
\hline Female, 20-39 & $111(111-112)$ & $108(106-110)$ & $106(104-108)$ \\
\hline Male, 40-59 & $129(128-130)$ & $119(117-122)$ & $120(118-122)$ \\
\hline Female, 40-59 & $123(123-124)$ & $116(114-118)$ & $115(113-117)$ \\
\hline Male, 60-79* & $140(140-141)$ & $123(121-126)$ & $125(124-127)$ \\
\hline Female, 60-79* & $140(139-141)$ & $122(117-128)$ & $129(128-131)$ \\
\hline $\begin{array}{l}\text { People with no } \\
\text { hypertension }\end{array}$ & $117(117-117)$ & $113(112-114)$ & $113(112-114)$ \\
\hline $\begin{array}{l}\text { People with untreated } \\
\text { hypertension }\end{array}$ & $146(145-147)$ & $148(144-151)$ & $148(144-151)$ \\
\hline $\begin{array}{l}\text { People with treated } \\
\text { hypertension }\end{array}$ & $145(143-147)$ & $124(122-126)$ & $128(126-130)$ \\
\hline \multicolumn{4}{|l|}{ Diastolic } \\
\hline \multicolumn{4}{|l|}{ Sex } \\
\hline Male & $79(79-80)$ & 75 (73-76) & 77 (77-78) \\
\hline Female & $74(74-74)$ & $72(71-73)$ & $74(73-75)$ \\
\hline \multicolumn{4}{|l|}{ Age groupings, yr } \\
\hline Male, 20-39 & $78(77-78)$ & $72(70-73)$ & 75 (74-76) \\
\hline Female, 20-39 & $71(71-71)$ & $71(60-69)$ & $72(70-73)$ \\
\hline Male, 40-59 & $83(82-83)$ & $77(76-78)$ & $80(79-81)$ \\
\hline Female, 40-59 & 78 (78-79) & $74(73-75)$ & 75 (74-76) \\
\hline Male, 60-79* & $81(81-81)$ & $76(74-78)$ & 77 (76-78) \\
\hline Female, 60-79* & 79 (78-79) & $71(69-73)$ & $75(74-76)$ \\
\hline $\begin{array}{l}\text { People with no } \\
\text { hypertension }\end{array}$ & $74(74-74)$ & $72(71-73)$ & 75 (74-75) \\
\hline $\begin{array}{l}\text { People with untreated } \\
\text { hypertension }\end{array}$ & 89 (89-90) & $87(85-90)$ & $89(87-90)$ \\
\hline $\begin{array}{l}\text { People with treated } \\
\text { hypertension }\end{array}$ & $85(84-86)$ & $76(75-77)$ & 77 (76-79) \\
\hline \multicolumn{4}{|c|}{$\begin{array}{l}\text { Note: } \mathrm{BP}=\text { blood pressure, } \mathrm{Cl}=\text { confidence interval, } \mathrm{CHHS}=\text { Canadian Heart Health Survey, } \\
\mathrm{CHMS}=\text { Canadian Health Measures Survey, ON-BP = Ontario Survey on the Prevalence and } \\
\text { Control of Hypertension. } \\
\text { *The upper age limit in the CHHS was } 74 \text { years. }\end{array}$} \\
\hline
\end{tabular}


improvements are consistent with data ${ }^{15}$ that showed marked increases in the use of antihypertensive drugs in Canada since the late 1990s (prescribing patterns that were not seen to the same extent in the US). ${ }^{16}$ Although these prescribing changes happened at the same time as the initiation of the Canadian Hypertension Education Program,, 517 it is not possible to say whether the program was directly responsible for the improvements in the control of hypertension.

Contrary to analyses of physician billing databases, ${ }^{18}$ we did not find a substantial change in the prevalence of hypertension among community-dwelling adult Canadians between 1992 and 2009. A recent report using data from the US National Health and Nutrition Examination Survey (NHANES) also reported a stable prevalence of hypertension between 1999 and $2008 .^{10}$ Physical measures surveys such as the CHMS and the NHANES focus on communitydwelling adults, whereas analyses of administrative databases capture all individuals, including patients living in long-term care facilities. It is therefore not surprising that estimates of the prevelance of hypertension are higher in analyses of administrative data. However, we believe that our findings suggest that at least some of the apparent increase in the incidence and prevalence of hypertension that are seen in analyses of administrative data may represent greater awareness of hypertension rather than an actual change in the underlying epidemiology. The marked decrease in the proportion of Canadians with hypertension who were unaware of their condition that we saw between 1992 and 2009 is entirely consistent with the trends seen over the past decade in the National Population Health Surveys and the Canadian Community Health Surveys. ${ }^{17}$

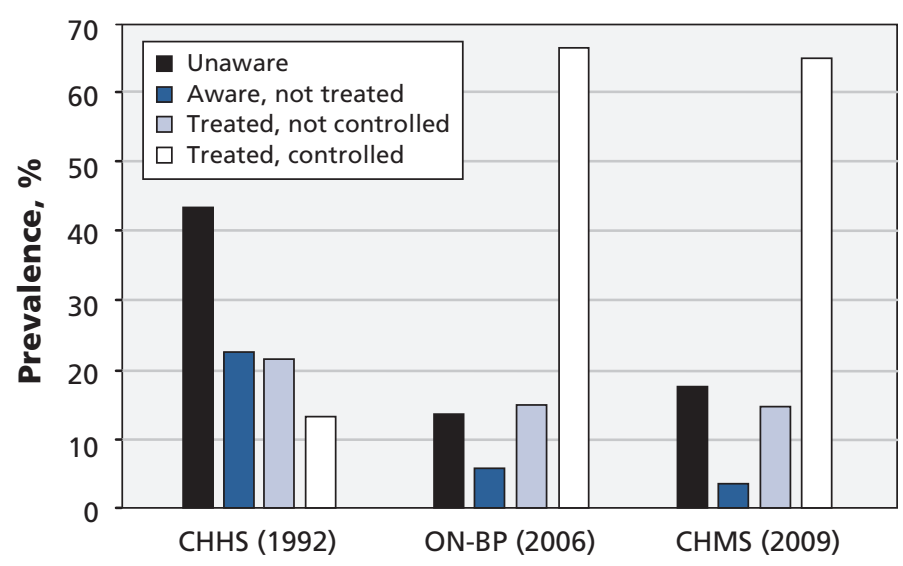

Figure 1: Rates of hypertension awareness, treatment and control among Canadians with hypertension from 1992 to 2009. CHHS = Canadian Heart Health Survey, ON-BP = Ontario Survey on the Prevalence and Control of Hypertension, CHMS = Canadian Health Measures Survey.
We found that people with treated hypertension and participants without hypertension had substantially lower systolic blood pressures in 2009 than in 1992. This result suggests that not all of the benefits we have observed in Canada are related to the use of antihypertensive medications. Indeed, we found that people without hypertension showed a 4-mm Hg drop in average systolic blood pressure between 1992 and 2009, which suggests a shift in the underlying population distribution of blood pressure. This is surprising, given the increasing rates of obesity and diabetes in the Canadian population over the past two decades and data from the NHANES that showed a $1.5-\mathrm{mm} \mathrm{Hg}$ increase in systolic blood pressure among Americans without hypertension over the same period..$^{10}$ It is possible that increases in physical activity and improvements in diet (www.statcan.gc.ca/pub/21-020 -x/21-020-×2009001-eng.htm [accessed 2010 Sept. 3]) may have led to this change, but further study is needed. ${ }^{19}$

Most of the participants with blood pressure that was being treated but was not controlled were classified as such on the basis of their systolic blood pressure. This is not surprising, since education efforts have traditionally placed more emphasis on diastolic blood pressure (indeed, explicit targets for systolic blood pressure did not appear in the Canadian national guidelines until 2001), and several surveys have shown that clinicians tend to accept higher systolic blood pressures than are recommended in the guidelines before prescribing or increasing antihypertensive medications, particularly among older patients. ${ }^{20-22}$ However, it has been estimated that the optimal control of systolic blood pressure in people with hypertension could prevent almost half of all atherosclerotic cardiovascular events in North America. ${ }^{23}$

Finally, among people with hypertension, those who also had cardiovascular or cerebrovascular disease were more likely to have their blood pressure under control. This is encouraging, as it suggests that either Canadian physicians appropriately target more intensive therapy to patients at higher risk or that patients at higher risk are more compliant with their therapy. A similar result was seen in a chart audit of more than 10000 patients from primary care practices in southwestern Ontario, ${ }^{24}$ but such a result has not been seen in other countries. ${ }^{25-27}$ This is important, as targeting therapy toward people with established disease or multiple cardiovascular risk factors will lead to greater absolute benefits than treatment strategies targeting only single risk factors. ${ }^{28}$

\section{Limitations}

Although our analyses are based on nationally representative data, there are some limitations to our 
study. The proportion of people with hypertension who were aware of their condition is likely to be an overestimation because "regularly taking antihypertensive medication in the past month" was part of the case definition. However, the measurement of blood pressure only once during these surveys will tend to underestimate control rates and overestimate prevalence compared with 24-hour ambulatory blood pressure monitoring. ${ }^{29}$

In addition, people with isolated office hyper- tension may have been misclassified as having uncontrolled hypertension, and people with masked hypertension may have been misclassified as having controlled hypertension. Regardless, the definitions for hypertension and hypertension control were identical among the three surveys (as well as in the NHANES).

One would expect the blood pressures recorded during the CHMS and ON-BP to be about $3 \mathrm{~mm} \mathrm{Hg}$ lower than the blood pressures recorded

Table 2: Rates of awareness, treatment and control of hypertension among participants in three population-based health surveys, stratified by comorbidities, from 1992 to 2009

\begin{tabular}{|c|c|c|c|}
\hline & $\begin{array}{c}\text { CHHS (1986-1992) } \\
N=22314\end{array}$ & $\begin{array}{l}\text { ON-BP (2006) } \\
N=2551\end{array}$ & $\begin{array}{c}\text { CHMS (2007-2009) } \\
N=3487\end{array}$ \\
\hline Subgroups & $\%(95 \% \mathrm{Cl}) *$ & $\%(95 \% \mathrm{Cl}) *$ & $\%(95 \% \mathrm{Cl}) *$ \\
\hline Overall, no.t & 5127 & 651 & 890 \\
\hline Unaware & $43.2(39.5-46.9)$ & $13.5(8.9-18.0)$ & $17.4(14.0-21.5)$ \\
\hline Aware, not treated & $22.3(19.4-25.2)$ & $5.7(2.7-8.8)$ & $3.5(2.2-5.4)$ \\
\hline Treated, not controlled & $21.4(18.5-24.3)$ & $14.8(10.2-19.4)$ & $14.4(11.3-18.5)$ \\
\hline Treated and controlled & $13.2(10.7-15.7)$ & $66.0(59.8-72.2)$ & $64.6(60.0-69.2)$ \\
\hline $\begin{array}{l}\text { No prior MI, stroke or } \\
\text { dyslipidemia, no. }\end{array}$ & 2295 & 346 & 402 \\
\hline Unaware & $52.3(47.2-57.4)$ & $21.8(14.1-29.5)$ & $25.6(19.2-33.4)$ \\
\hline Aware, not treated & $21.2(17.5-24.9)$ & $10.5(4.5-16.5)$ & $4.3(2.1-8.9)$ \\
\hline Treated, not controlled & $15.1(11.8-18.5)$ & $10.0(5.9-14.1)$ & $16.6(11.9-22.7)$ \\
\hline Treated and controlled & $11.3(7.9-14.7)$ & $57.7(49.8-65.6)$ & $53.5(47.4-59.4)$ \\
\hline $\begin{array}{l}\text { Prior MI or dyslipidemia, } \\
\text { no. }\end{array}$ & 2832 & 305 & 488 \\
\hline Unaware & $47.0(42.6-51.5)$ & $6.0(1.9-10.1)$ & $12.9(9.9-16.8)$ \\
\hline Aware, not treated & $20.8(17.6-24.0)$ & $1.5(0.0-3.3)$ & $2.9(1.9-4.4)$ \\
\hline Treated, not controlled & $18.8(15.2-22.5)$ & $19.1(10.2-28.0)$ & $19.9(15.6-25.1)$ \\
\hline Treated and controlled & $13.3(10.3-16.3)$ & $73.4(63.6-83.1)$ & $64.3(58.2-70.0)$ \\
\hline Diabetes mellitus, no. & 734 & 124 & 176 \\
\hline Unaware & $43.3(32.9-53.7)$ & $3.7(0.0-7.7)$ & $16.6(11.6-23.1)$ \\
\hline Aware, not treated & $21.5(14.8-28.2)$ & 0.0 & $1.1(0.1-14.5)$ \\
\hline Treated, not controlled & $33.1(24.2-41.7)$ & $59.7(44.0-75.3)$ & $36.8(30.6-43.5)$ \\
\hline Treated and controlled & $2.1(0.4-3.9)$ & $36.6(21.6-51.7)$ & $45.5(38.9-52.3)$ \\
\hline Prior MI or stroke, no. & 606 & 77 & 111 \\
\hline Unaware & $25.7(16.6-34.7)$ & $5.8(0.0-12.9)$ & $3.8(1.3-10.4)$ \\
\hline Aware, not treated & $12.2(6.9-17.5)$ & $1.3(0.0-3.9)$ & $1.2(0.3-4.7)$ \\
\hline Treated, not controlled & $40.1(27.9-52.3)$ & $18.7(4.4-33.1)$ & $15.8(10.7-22.7)$ \\
\hline Treated and controlled & $22.1(13.5-30.7)$ & $74.2(56.8-91.6)$ & $79.3(71.0-85.6)$ \\
\hline Dyslipidemia, no. & 2562 & 277 & 435 \\
\hline Unaware & $40.7(35.2-46.2)$ & $4.8(1.5-8.2)$ & $13.3(10.1-17.4)$ \\
\hline Aware, not treated & $22.9(18.5-27.4)$ & $1.3(0.0-3.2)$ & $3.2(2.0-4.9)$ \\
\hline Treated, not controlled & $20.4(16.9-24.0)$ & $19.7(9.5-30.0)$ & $20.2(15.5-25.8)$ \\
\hline Treated and controlled & $15.9(11.4-20.4)$ & $74.2(63.8-84.5)$ & $63.4(56.9-69.3)$ \\
\hline \multicolumn{4}{|c|}{$\begin{array}{l}\text { Note: } \mathrm{CHHS}=\text { Canadian Heart Health Survey, } \mathrm{CHMS}=\text { Canadian Health Measures Survey, } \mathrm{CV}=\text { cardiovascular, } \mathrm{MI}=\text { myocardial } \\
\text { infarction, ON-BP = Ontario Survey on the Prevalence and Control of Hypertension. } \\
\text { *Unless otherwise specified. } \\
\text { tThe values for } n \text { provided for each comorbidity group are from the survey sample, but the percentages for awareness, } \\
\text { treatment and control have been weighted to reflect the general population from which each survey sampled. }\end{array}$} \\
\hline
\end{tabular}


during the CHHS. The blood pressures recorded in the CHMS and ON-BP were averages of at least five automated blood pressure readings using a BpTRU machine without an observer present, whereas blood pressure measurements in the CHHS were taken from four readings using manual mercury sphygmomanometers. ${ }^{13}$ We took this discrepancy into account by adjusting all BpTRU measurements using regression equations to estimate the equivalent manual reading, thus allowing comparisons across surveys. ${ }^{13}$ Although the regression equations we used for these adjustments have been previously independently validated, ${ }^{13}$ and although the coefficients of correlation were high for both systolic $\left(r^{2}=0.84\right)$ and diastolic $\left(r^{2}=\right.$ 0.70 ) blood pressures, it should be noted that studies are ongoing to definitively establish the relation between BpTRU measurements and 24-hour ambulatory measurements.

If different cutoffs to define hypertension in surveillance studies are chosen in the future, then estimates of prevalence and control will need to be recalculated. ${ }^{30}$

Finally, as there is debate over the appropriate blood pressure targets for people with diabetes, ${ }^{31}$ we used a definition of $140 / 90 \mathrm{~mm} \mathrm{Hg}$ to define hypertension control for all people for our primary analysis, but we also reported prevalence and control rates if $130 / 80 \mathrm{~mm} \mathrm{Hg}$ was used for people with diabetes.

\section{Implications}

In an earlier analysis of mortality data from countries with established market economies, we showed that those countries with the highest rates of control of hypertension and the lowest mean blood pressures had the lowest rates of death from stroke, myocardial infarction and heart failure. ${ }^{32}$ In that context, the findings from the ON-BP and the CHMS are particularly encouraging and provide a potential explanation for the statistically significantly greater-thanexpected reductions in cardiovascular mortality seen in Canada during the past decade.

A recent analysis of data from 5.4 million people from 199 countries documented that mean levels of systolic blood pressure in Canada were now among the lowest in the world. ${ }^{33}$ However, despite marked improvements in rates for the control of hypertension over the past two decades, one-third of community-dwelling Canadian adults with hypertension still have blood pressures that are higher than the currently recommended targets, and cardiovascular disease remains the most common cause of premature death and disability in Canada. Continued efforts to optimize the management of hypertension are necessary to further reduce the burden of cardiovascular disease in Canada. More- over, without continued vigilance and reinforcement after improvements in practice have been made, quality of care will deteriorate over time. ${ }^{34}$

\section{References}

1. Lawes CMM, Vander Hoorn S, Law MR, et al. Blood pressure and the global burden of disease 2000. Part II: Estimates of attributable burden. J Hypertens 2006;24:423-30.

2. Lewington S, Clarke R, Qizilbash N, et al; Prospective Studies Collaboration. Age-specific relevance of usual blood pressure to vascular mortality: a meta-analysis of individual data for one million adults in 61 prospective studies. Lancet 2002;360:1903-13.

3. Law MR, Morris JK, Wald NJ. Use of blood pressure lowering drugs in the prevention of cardiovascular disease: meta-analysis of 147 randomised trials in the context of expectations from prospective epidemiological studies. BMJ 2009;338:b1665.

4. McAlister FA. The treatment of hypertension in Canada: Are we making progress? CMAJ 1999;161:713-4.

5. Campbell NRC, Tu K, Brant R, et al. The impact of the Canadian Hypertension Education Program on antihypertensive prescribing trends. Hypertension 2006;47:22-8.

6. Campbell NRC, Brant R, Johansen H, et al. Increases in antihypertensive prescriptions and reductions in cardiovascular events in Canada. Hypertension 2009;53:128-34.

7. Leenen FH, Dumais J, McInnis NH, et al. Results of the Ontario survey on the prevalence and control of hypertension. CMAJ 2008;178:1441-9.

8. Kearney PM, Whelton M, Reynolds K, et al. Worldwide prevalence of hypertension: a systematic review. J Hypertens 2004;22:11-19.

9. Pereira M, Lunet N, Azevedo A, et al. Differences in prevalence, awareness, treatment, and control of hypertension between developing and developed countries. J Hypertens 2009;27:963-75.

10. Egan BM, Zhao Y, Axon RN. US trends in prevalence, awareness, treatment, and control of hypertension, 1988-2008. JAMA 2010;303:2043-50.

11. Joffres MR, Ghadirian P, Fodor JG, et al. Awareness, treatment, and control of hypertension in Canada. Am J Hypertens 1997; 10:1097-102.

12. Wilkins K, Campbell NRC, Joffres MR, et al. Blood pressure in Canadian adults. Health Rep 2010;21:37-46.

13. Myers MG, McInnis NH, Fodor GJ, et al. Comparison between an automated and manual sphygmomanometer in a population survey. Am J Hypertens 2008;21:280-3.

14. Rust KF, Rao JNK. Variance estimation for complex surveys using replication techniques. Stat Methods Med Res 1996;5:283-310.

15. Tu K, Campbell NRC, Durong-Hua M, et al. Hypertension management in the elderly has improved: Ontario prescribing trends, 1994 to 2002. Hypertension 2005;45:1113-8.

16. Muntner P, Krousel-Wood M, Hyre A, et al. Antihypertensive prescription for newly treated patients before and after the main antihypertensive and lipid-lowering treatment to prevent heart attack trial results and seventh report of the joint national committee on prevention, detection, evaluation, and treatment of high blood pressure guidelines. Hypertension 2009;53:617-23.

17. McAlister FA, Feldman RD, Wyard K, et al. Campbell $\mathrm{N}$ for the CHEP Outcomes Research Task Force. The impact of the Canadian Hypertension Education Program in its first decade. Eur Heart J 2009;30:1434-9.

18. Tu K, Chen Z, Lipscombe LL. Prevalence and incidence of hypertension from 1995 to 2005 : a population-based study. CMAJ 2008;178:1429-35.

19. Joffres MR, Campbell NRC, Manns B, et al. Estimate of the benefits of a population-based reduction in dietary sodium additives on hypertension and its related health costs in Canada. Can J Cardiol 2007;23:437-43.

20. Hyman DJ, Pavlik VN. Self-reported hypertension treatment practices among primary care physicians. Arch Intern Med 2000;160:2281-6.

21. Oliveria SA, Lapuerta P, McCarthy BD, et al. Physician-related barriers to the effective management of uncontrolled hypertension. Arch Intern Med 2002;162:413-20.

22. McAlister FA, Laupacis A, Teo KK, et al. A survey of clinician attitudes and management practices in hypertension. J Hum Hypertens 1997;11:413-9.

23. Wong ND, Thakral G, Franklin SS, et al. Preventing heart disease by controlling hypertension: impact of hypertensive subtype, stage, age, and sex. Am Heart J 2003;145:888-95.

24. Petrella RJ, Merikle E. A retrospective analysis of the prevalence and treatment of hypertension and dyslipidemia in southwestern Ontario, Canada. Clin Ther 2008;30:1145-54.

25. Thoenes M, Neuberger HR, Volpe M, et al. Antihypertensive 
drug therapy and blood pressure control in men and women: an international perspective. J Hum Hypertens 2010;24:336-44.

26. Wang YR, Alexander GC, Stafford RS. Outpatient hypertension treatment, treatment intensification, and control in Western Europe and the United States. Arch Intern Med 2007;167:141-7.

27. Belletti DA, Zacker C, Wogen J. Effect of cardiometabolic risk factors on hypertension management: a cross-sectional study among 28 physician practices in the United States. Cardiovasc Diabetol 2010;9:7.

28. Emberson J, Whincup P, Morris R, et al. Evaluating the impact of population and high-risk strategies for the primary prevention of cardiovascular disease. Eur Heart J 2004;25:484-91.

29. Birkett NJ. The effect of alternative criteria for hypertension on estimates of prevalence and control. J Hypertens 1997;15:237-44.

30. Leenen FHH, Schiffrin EL. Control rates of hypertension in North America. Hypertension 2010;56:571-2.

31. Cushman WC, Evans GW, Byington RP, et al; The ACCORD Study Group. Effects of intensive blood-pressure control in type 2 diabetes mellitus. N Engl J Med 2010;362:1575-85.

32. McAlister FA, Kelly N, Chen G, et al.; the Canadian Hypertension Education Program Outcomes Research Task Force and Blood Pressure Canada. Canadian Hypertension Education Program Evaluation Project: a comparison of changes in Canadian hypertension treatment, hypertension diagnosis, and cardiovascular disease rates to other national hypertension management programs. A report for the Public Health Agency of Canada, Management Division, Centre for Disease Prevention and Control. 2009 Mar. 31.

33. Danaei G, Finucane MM, Lin JK, et al. National, regional, and global trends in systolic blood pressure since 1980: systematic analysis of health examination surveys and epidemiological studies with 786 country-years and 5.4 million participants. Lancet 2011;377:568-77.

34. Majumdar SR, McAlister FA, Furberg CD. From publication to practice in chronic cardiovascular disease - the long and winding road. J Am Coll Cardiol 2004;43:1738-42.

Affiliations: From the Division of General Internal Medicine (McAlister), University of Alberta, Edmonton, Alta.; Statistics Canada (Wilkins, Johansen), Ottawa, Ont.; Simon Fraser University (Joffres), Vancouver, BC; the Ottawa Heart Institute (Leenen, Fodor), University of Ottawa, Ottawa, Ont.; the Public Health Agency of Canada (Gee), Ottawa, Ont.; the Children's Hospital of Eastern Ontario Research Institute (Tremblay), Ottawa, Ont.; the Departments of Medicine, Community Health Sciences and of Pharmacology and Therapeutics (Walker, Campbell), Libin Cardiovascular Institute, University of Calgary, Calgary, Alta.

Contributors: All of the authors conceived the study; Kathryn Wilkins, Michel Joffres, and Frans Leenen conducted the analyses; all of the authors interpreted the data; Finlay McAlister wrote the first draft of the manuscript; all of the authors reviewed and revised the manuscript and approved the final version submitted for publication.

Funding: The Canadian Heart Health Survey was funded by the National Health Research Development Program of Health Canada, the provincial ministries of health, and the Heart and Stroke Foundation of Canada; the Ontario Survey on the Prevalence and Control of Hypertension was funded by the Heart and Stroke Foundation of Ontario; the Canadian Health Measures Survey was done by Statistics Canada in partnership with Health Canada and the Public Health Agency of Canada with funding from the Canadian Government.

Finlay McAlister is supported by an Alberta Heritage Foundation for Medical Research Health Scholar Award. Frans Leenen holds the Pfizer Chair in Hypertension Research supported by Pfizer Canada, the University of Ottawa Heart Institute Foundation and the Canadian Institutes of Health Research. Norm Campbell holds the Canada Chair in Hypertension Prevention and Control funded by the Canadian Institutes of Health Research, the Canadian Hypertension Society and Sanofi-Aventis.

Acknowledgements: The authors thank Dr. Oliver Baclic, Dr. Cynthia Robitaille and Dr. Christina Bancej from the Public Health Agency of Canada for comments on earlier versions of this manuscript. 